\title{
Frequent silence of chromosome 9p, homozygous $D O C K 8$, DMRT1 and DMRT3 deletion at 9p24.3 in squamous cell carcinoma of the lung
}

\author{
JI UN KANG ${ }^{1}$, SUN HOE KOO ${ }^{2}$, KYE CHUL KWON ${ }^{2}$ and JONG WOO PARK ${ }^{2}$ \\ ${ }^{1}$ Department of Pathology, Columbia University Medical Center, New York, NY 10032, USA; ${ }^{2}$ Department of Laboratory \\ Medicine, Chungnam National University College of Medicine, Daejeon 301-721, Republic of Korea
}

Received February 2, 2010; Accepted March 24, 2010

DOI: 10.3892/ijo_00000681

\begin{abstract}
Chromosomal alterations are a major genomic force contributing to the development of lung cancer. We subjected 22 cases of squamous cell carcinoma of the lung (SCC) to whole-genome microarray-CGH (resolution, $1 \mathrm{Mb}$ ) to identify critical genetic landmarks that might be important mediators in the formation or progression of SCC. On a genome-wide profile, copy number losses $\left(\log _{2}\right.$ ratio <-0.25) on chromosome 9p occurred in $72.7 \%$ (16/22) of the SCC cases, and the delineated minimal common region was 9p24.3-p21.1. The progression of SCC to advanced stages or poorly differentiated malignancy was significantly associated with an increase in the copy number losses on $9 \mathrm{p}(\mathrm{P}=0.033)$. More specifically, 2 distinct homozygous deletion (HD) loci $\left(\log _{2}\right.$ ratio <-1) were identified as novel loci for candidate tumor suppressor genes (TSGs) in SCC: one, spanning $128 \mathrm{kbp}$ on $9 \mathrm{p} 21.1[4.5 \%(1 / 22)]$ and the other, spanning approximately $200 \mathrm{kbp}$ on $9 \mathrm{p} 24.3$ [13.6\% (3/22)]. The HDs at 9p24.3 was found to contain the putative TSG, DOCK 8 and 2 possible candidate TSGs, DMRT1 and DMRT3. Quantitative real-time PCR (qRT-PCR) analysis demonstrated the array-CGHdetected potential candidate genes DMRT1, DMRT3 and DOCK8, at 9p24.3 were under-expressed in SCCs. Our study indicated that chromosome $9 \mathrm{p}$ loss is the hallmark of SCC, and DMRT1,DMRT3 and DOCK8 genes at 9p24.3 might be of interest for the study of the pathophysiology of SCC as potential targets for therapeutic measures.
\end{abstract}

\section{Introduction}

Non-small cell lung cancer (NSCLC) is responsible for the highest number of cancer-related deaths worldwide (1), and

Correspondence to: Dr Sun Hoe Koo, Chungnam National University Hospital, 640 Daesadong, Jung-Gu, Taejeon, 301-721 Republic of Korea

E-mail: shkoo@cnu.ac.kr

Key words: squamous cell carcinoma of the lung, microarray $\mathrm{CGH}$, copy number loss, homozygous deletion, tumor suppressor gene, quantitative real-time PCR the 2 main types of NSCLC, namely adenocarcinoma and squamous cell carcinoma (SCC), account for over half of the NSCLC cases. SCC of the lung is characterized by a complex pattern of cytogenetic and molecular genetic changes; chromosomal aberrations are a hallmark of cancer cells and are highly prevalent in SCC (2). Although many studies have been performed to evaluate the genetic events associated with the development and progression of SCC $(3,4)$, its molecular mechanism still remains to be understood, and identification of the predictive markers is crucial.

Homozygous deletions (HDs) are major genomic forces contributing to the development of many solid tumors and provide an important resource for identifying the location of candidate tumor suppressor genes (TSGs). In cancer genomes, such HDs can cause the inactivation of genes with tumor suppressor activity and thus contribute to cancer development and progression $(5,6)$. Therefore, detection of specific gene deletions in tumor cells can lead to the identification of genes putatively involved in growth control and tumorigenesis.

Previous analyses of the SCC genome with low-resolution chromosomal or BAC array-CGH have demonstrated several typical regions with genomic deletions. The most common HDs in SCC have been repeatedly detected on 3p, 4q, 8p, 9p and 17p (7-9). Many significant genes that map to these regions have previously been described to be deleted in SCC (e.g., BRCA1, PTEN, TP53 and CDKN2A/p16) (5,10-12) and are known to promote the carcinogenesis of SCC; however, little is known about the specific underlying genes that affect tumorigenesis in SCC. Furthermore, the genomic markers that predict aggressive clinical behavior of SCC still remain to be identified. In this study, we therefore conducted a highresolution array-CGH scanning for HDs in 22 SCC cases to identify the critical TSGs that could play an important role in SCC progression.

\section{Materials and methods}

Patient specimens. Twenty-two SCC of lung cancer patients were analyzed by array-based CGH. None of these patients had been administered preoperative chemotherapy or radiation. All tumors were histologically classified according to the standard World Health Organization (WHO) criteria. 
Clinical staging was performed according to the International Union Against Cancer (UICC) recommendations. All cases were reviewed by pathologists to verify the original histopathological diagnosis, tumor stage, tumor differentiation and lymph node metastasis. This study was reviewed and approved by the Institutional Review Board of the Chungnam National University Hospital. Written informed consent was obtained from each patient according to the institutional regulations.

Touch preparations were performed as described previously (13). The genomic DNA was extracted using a Genomic DNA purification kit (Promega, Madison, WI, USA), with some modifications as described before (14): commercial genomic DNA was used as a reference (Human Genomic DNA: Female; Promega; cat. no. G1521).

Array-CGH. Array-CGH was run on the MacArray ${ }^{\mathrm{TM}}$ Karyo 4000 K BAC-chip (Macrogen, Seoul, Korea; http:// www.macrogen.co.kr) (3,14-18), consisting of 4,046 human BACs applied in duplicate and a resolution of $1 \mathrm{Mbp}$. All clones were two-end sequenced using an ABI PRISM 3700 DNA Analyzer (Applied Biosystems, Foster City, CA), and their sequences were blasted (using BLAST; http://blast.ncbi. nlm.nih.gov/Blast.cgi). The information on each individual clone was obtained from the UCSC Genome Bioinformatics database [http://genome.ucsc.edu; Build 36, Version Mar. 2006 (hg18)].

Hybridizations were carried out using a standard direct method as described previously (13). Briefly, $500 \mathrm{ng}$ of normal male DNA (reference) and digested tumor DNA (test) were labeled with Cy5-dCTP and Cy3-dCTP, respectively, by random primed labeling (Array CGH Genomic Labeling System; Invitrogen, CA, USA). The labeled DNA was then washed, its yield was quantified, and the appropriate control and test samples were combined in equal amounts. The labeled probe and human Cot-I DNA were mixed and dissolved in the hybridization solution. Hybridizations were performed in a sealed chamber for $48 \mathrm{~h}$ at $37^{\circ} \mathrm{C}$. After hybridization, the hybridized array slides were scanned on a GenePix 4200A two-color fluorescent scanner (Axon Instruments, Union City, CA, USA). The acquired images were analyzed using GenePix Pro 4.1 imaging software (Axon Instruments).

Data analysis. We applied LOWESS normalization, a form of smoothing adjustment that removes intensity-dependent dye bias. The spot quality criteria were set as foreground-tobackground $>3.0$ and standard deviation of triplicates $<0.2$. Breakpoint detection and status assignment of the genomic regions was performed using GLAD software (19). The average $\log _{2} \mathrm{Cy} 3 / \mathrm{Cy} 5$ signal ratios of the triplicate $\mathrm{BAC}$ clones were calculated for each sample, and chromosomal aberrations were classified as a gain or loss when the normalized $\log _{2}$ Cy $3 / \mathrm{Cy} 5$ ratio was $>0.25$ or $<-0.25$, respectively. Homozygous deletion of clones was defined as an intensity ratio of $<-1$ on the $\log _{2}$ scale $(20-22)$. This threshold value was determined empirically as a value 3 -fold that of the standard deviation calculated from 30 normal male to normal females in hybridization experiments. The software MAC viewer (v1 .6.6), CGH-Explorer 2.55 and Avadis 3.3 Prophetic were used for graphical illustration and image analysis of the
array-CGH data. The Benjamini-Hochberg false discovery rate (FDR) was applied for multiple testing correction for the high number of false-positive calls. The R 2.2.1 package of the Bioconductor Project (http://www.bioconductor.org) was used for the detection of the frequency of gain or loss and for statistical analysis.

Statistical analysis. The differences in the $\log _{2}$ ratios as well as in the Chi-square test were used for group comparisons of significant loss of genomic content. We also applied Fisher's exact test using two categories, i.e., normal and abnormal (loss), along with the null hypothesis that 'the relative proportions of each of the 2 imbalance categories is the same between the groups'. For comparison, 3 types of clinical variables were treated as categorical variables, including the lymph node status (N1/N2 vs. N0), histological differentiation (poorly differentiated vs. well differentiated/moderately differentiated), and the tumor stages (I, II and III). The counts of abnormal versus normal were summarized from the clinicopathological parameters of SCC for each BAC, providing $2 \times 2$ tables for analysis. The correlation between the BAC chip and quantitative real-time PCR (q-RT-PCR) data was determined by Pearson correlation analysis $(\mathrm{P}<0.05)$. In all statistical analyses, $\mathrm{P}<0.05$ was considered statistically significant.

Quantitative real-time PCR analysis. In order to validate the array-CGH results, we performed a quantitative real-time PCR analysis using the ABI PRISM 7900HT Sequence Detection system and TaqMan Gene Expression assays according to the manufacturer's instructions (Applied Biosystems, Foster City, CA, USA).

Amplifications were performed using the Universal Master Mix (Applied Biosystems) and included 40 cycles under the following cycling conditions: denaturation for $15 \mathrm{sec}$ at $95^{\circ} \mathrm{C}$ and annealing/amplification for $1 \mathrm{~min}$ at $60^{\circ} \mathrm{C}$ after initial activation for $10 \mathrm{~min}$ at $95^{\circ} \mathrm{C}$. All samples were amplified in triplicate, and the data were analyzed using Sequence Detector software (Applied Biosystems). We quantified the sample DNAs using standard curves generated using 3 reference DNAs. All data analysis was conducted using ArrayAssist ${ }^{\circledR}$ (Stratagene, La Jolla, CA, USA) and R (version 2.7.2). Normalized normal human pooled genomic DNAs (Promega) were used as the reference DNAs.

\section{Results}

Identification of chromosome 9p losses by genome-wide array-CGH. To identify the critical genetic markers associated with SCC progression, we performed a genome-wide array-CGH consisting of 4,046 BAC clones in a series of 22 SCC cases. A detailed overview of the clinicopathological data of the 22 SCC cases is summarized in Table I.

As the first step of our analysis, we decided to focus on chromosome $9 \mathrm{p}$, one of the most frequently lost $[72.7 \%$ $(16 / 22)]$ and hemizygous deleted [36.4\% (8/22)] regions in the SCC cases. In addition, the copy number losses of $9 \mathrm{p}$ were significantly affected by the progression of SCC to advanced stages or in poorly differentiated SCC. We reasoned that because of the high frequency of $9 \mathrm{p}$ chromosomal imba- 
Table I. Summary of clinicopathological data of the 22 SCC cases.

\begin{tabular}{|c|c|c|c|c|c|c|}
\hline \multirow[b]{2}{*}{ No. } & \multirow[b]{2}{*}{ Gender } & \multirow[b]{2}{*}{ Age } & \multirow[b]{2}{*}{$\begin{array}{c}\mathrm{WHO}^{\mathrm{a}} \\
\text { differentiation }\end{array}$} & \multicolumn{2}{|c|}{ TNM classification } & \multirow[b]{2}{*}{$\begin{array}{l}\text { Chromosomal } \\
\text { alterations on } 9 p\end{array}$} \\
\hline & & & & Lymph node stage & Tumor stage & \\
\hline 1 & M & 67 & WD & N1 & IIA & $9 \mathrm{p} 12$ \\
\hline 2 & $\mathrm{M}$ & 51 & WD & $\mathrm{N} 2$ & IIIA & $\begin{array}{l}\text { 9p12-p13.1, } \\
\text { 9p21.1-p21.3 }\end{array}$ \\
\hline 3 & M & 59 & MD & No & IB & $9 \mathrm{p} 13,9 \mathrm{p} 24.3$ \\
\hline 4 & M & 69 & PD & No & IB & $\begin{array}{l}\text { 9p12-p13.3, } \\
\text { 9p21.1-p24.3 }\end{array}$ \\
\hline 5 & M & 62 & MD & No & IA & $\begin{array}{l}\text { 9p12-p13.1, } \\
9 \text { p21.1-23 }\end{array}$ \\
\hline 6 & $\mathrm{~F}$ & 72 & MD & No & IB & 9p12-p13.1 \\
\hline 7 & M & 60 & WD & $\mathrm{N} 2$ & IIIA & - \\
\hline 8 & M & 64 & WD & No & IB & - \\
\hline 9 & M & 65 & MD & No & IB & - \\
\hline 10 & M & 65 & $\mathrm{PD}$ & $\mathrm{N} 1$ & IIB & 9p21.3-p24.3 \\
\hline 11 & M & 64 & MD & N1 & IIB & $\begin{array}{l}\text { 9p12-p13.3, } \\
\text { 9p21.1-p24.3 }\end{array}$ \\
\hline 12 & $\mathrm{M}$ & 65 & MD & N1 & IIB & - \\
\hline 13 & M & 64 & MD & No & IB & 9p12-p13.1 \\
\hline 14 & M & 64 & PD & No & IB & $9 \mathrm{p} 13.3,9 \mathrm{p} 24.3$ \\
\hline 15 & M & 66 & PD & $\mathrm{N} 2$ & IIIA & 9p12-p13.1 \\
\hline 16 & M & 74 & WD & No & IB & - \\
\hline 17 & $\mathrm{~F}$ & 72 & PD & No & IA & $9 \mathrm{p} 21.3-\mathrm{p} 24.3$ \\
\hline 18 & M & 74 & PD & No & IB & 9p21.3-p24.3 \\
\hline 19 & M & 69 & WD & No & IB & 9p12-p13.1 \\
\hline 20 & M & 55 & MD & $\mathrm{N} 2$ & IIIA & $\begin{array}{l}\text { 9p12-p13.1, } \\
\text { 9p22.3-p24.3 }\end{array}$ \\
\hline 21 & M & 90 & MD & N1 & IIB & $9 \mathrm{p} 12-\mathrm{p} 13.1$ \\
\hline 22 & $\mathrm{~F}$ & 69 & MD & No & IA & $9 \mathrm{p} 21.1-\mathrm{p} 21.3$ \\
\hline
\end{tabular}

${ }^{a} \mathrm{WD}$, well differentiated; MD, moderately differentiated; PD, poorly differentiated.

lances, this region is likely to harbor TSGs important for SCC development. The minimal common region of chromosome $9 \mathrm{p}$ was identified by genome-wide array-CGH to be located between BAC250_B08 and BAC131_L14.

In this region, we further clarified two common regions of loss at 9p21.3-p21.1 $(8 / 22 ; 36.4 \%)$, which harbors representative TSGs such as $C D K N 2 A / p 16, M T A P$ and TEK, and at 9p24.3-p24.1 $(8 / 22 ; 36.4 \%)$, which contains 18 possible target genes according to the information archived by human genome databases (http://genome.ucsc.edu/). A high frequency of hemizygous deletions $\left(-0.5<\log _{2}\right.$ ratio $\left.\leq-1\right)$ in the $9 \mathrm{p} 24.3-$ p21.1 region was also noted in $22.7 \%(5 / 22)$ of the cases. The detailed analysis of the above 2 distinct regions of alteration on chromosome $9 \mathrm{p}$ with the potential target genes in the 22 SCCs is summarized in Table II. Fig. 1A shows the frequency $(\%)$ of copy number changes on chromosome 9 , and Fig. 1B represents the weighted frequency (\%) diagram of the 9p24.3-p21.1 region in each of the 22 SCC cases.

Chromosome 9p losses in relation to the clinicopathological characteristics. To clarify the significance of the copy number losses on chromosome $9 \mathrm{p}$ in the pathogenesis of $\mathrm{SCC}$, we explored the relationship between chromosome 9p losses and the clinicopathological characteristics of the SCC cases. Chromosome arm 9p losses were strongly associated with the prognostic indicators of SCC, such as lymph node 


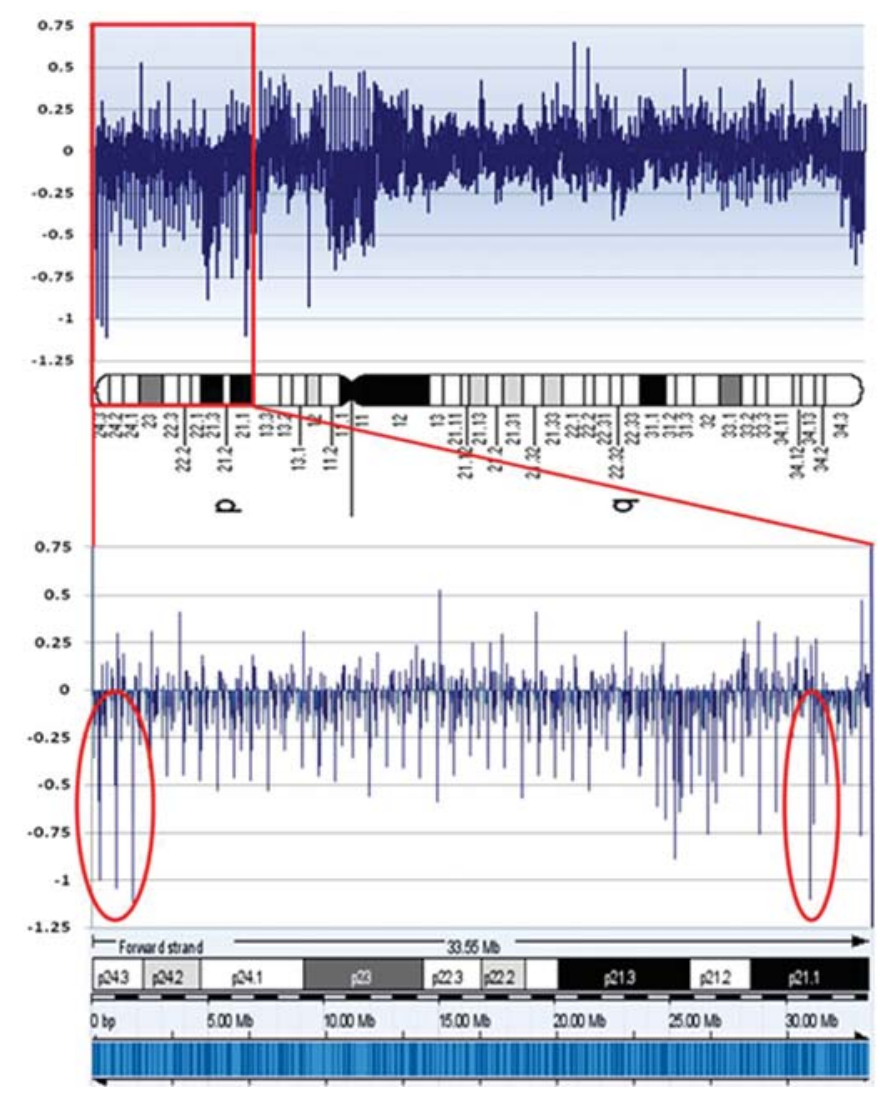

Figure 1. (A) Frequency of the copy number changes on chromosome 9 in the 22 SCC cases. The $\log _{2}$ ratios of all clones of chromosome 9 are plotted based on the chromosome position. The clones on chromosome 9 are arranged (pter-qter) based on the University of California Santa Cruz (UCSC) mapping positions. The genomic profiles of the 9p24.3-p21.1 region are highlighted in red. (B) Weighted frequency (\%) diagram of the 9p24.3-p21.1 region of all 22 SCCs. In the intensity ratio profiles, the $\mathrm{X}$-axis represents the map position of the corresponding clone, and the intensity ratios are assigned to the $\mathrm{Y}$-axis. A schematic representation of the cytogenetic bands, as well as a map position, is shown below the plot. The 2 homozygous deletion (HD) regions, i.e., 9p24.3 and 9p21.1, are highlighted in red.

metastasis status, histological differentiation and tumor stage. The prevalence of $9 p$ losses was greater in patients with lymph node metastasis than in patients without lymph node metastasis (N1/N2: $87.5 \%$ vs. N0: $62.3 \%$, respectively; Fig. 2A). The incidence of $9 p$ losses was also linked to the histological differentiation of SCC in that $9 \mathrm{p}$ losses were significantly more frequent in poorly differentiated $(\mathrm{PD})$ SCC than in well-differentiated (WD)/moderately differentiated (MD) tumors (100.0 vs. $53.8 \%$, respectively; $\mathrm{P}=0.033$; Fig. 2B).

More specifically, statistically significant differences were detected in the prevalence of copy number losses on $9 p$ among different tumor stages. The incidence of $9 p$ losses was directly related to the stage of disease progression and exhibited a tendency to increase with the advancement of the tumor stage, as shown in Fig. 2C ( $\mathrm{P}=0.033)$.

Target genes involved in homozygous deletions at 9p24.3p21.1 region in SCC. Since the most frequent genetic aberrations have already been identified, we focused on the identification of high-magnitude copy number changes, such as
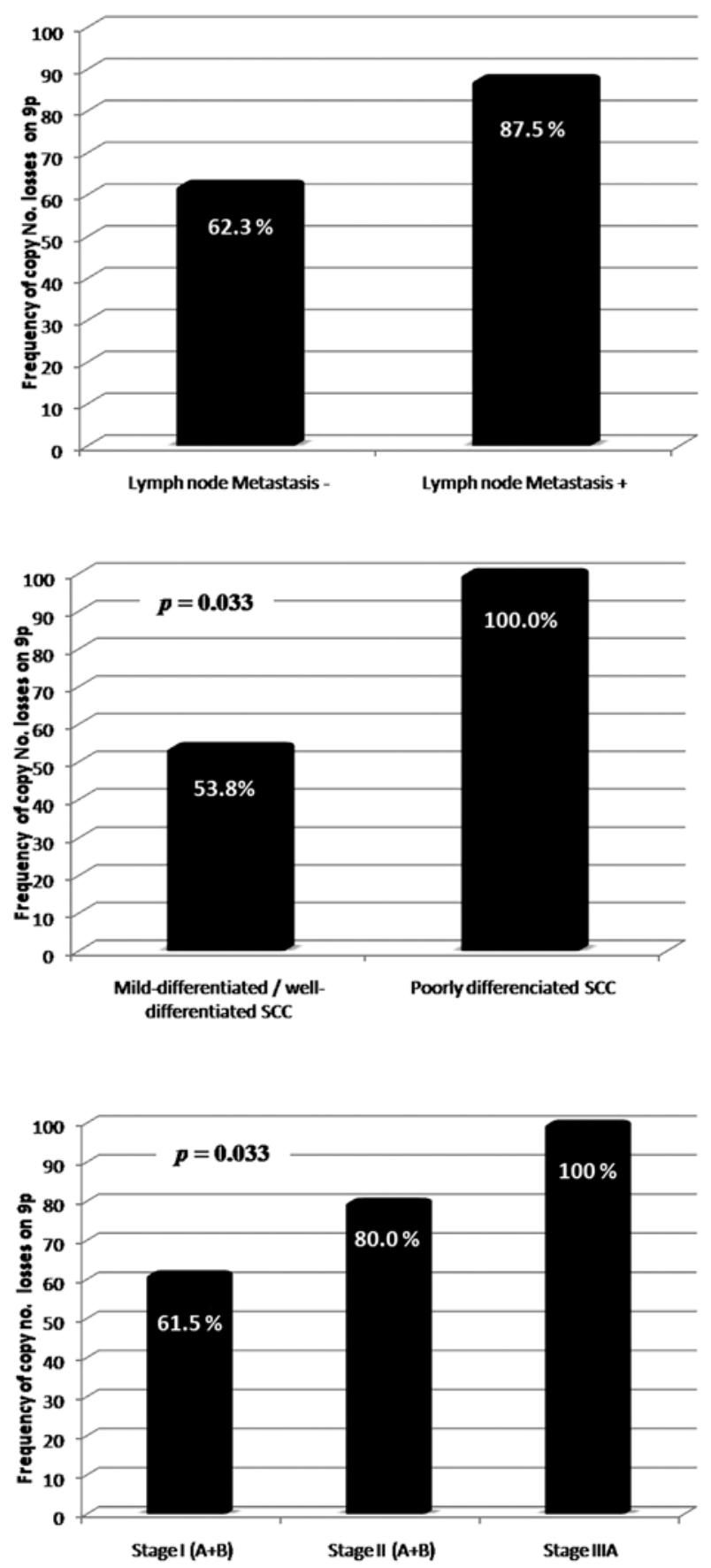

Figure 2. Chromosome 9p losses in relation to the clinicopathological characteristics of SCC. (A) The number of clones with copy number losses on $9 \mathrm{p}$ according to the lymph node metastasis status. Copy number losses on $9 \mathrm{p}$ were more prevalent in patients with lymph node metastasis than in patients without lymph node metastasis (N1/N2: $87.5 \%$ vs. N0: $62.3 \%$, respectively). (B) The average copy number loss on $9 \mathrm{p}$ according to the degree of histological differentiation of SCC. The average copy number loss on $9 p$ was significantly higher in poorly differentiated (PD) SCC than in well-differentiated (WD)/moderately differentiated (MD) tumors (100.0 vs. $53.8 \%$, respectively; $\mathrm{P}=0.033$ ). (C) Comparison of the incidence of copy number losses on 9p among SCC tumors of different stages (I, II, or IIIA). The percentage of clones with copy number losses on $9 \mathrm{p}$ was $61.5,80.0$ and $100.0 \%$ for stage I, II and IIIA tumors, respectively. There is a statistically significant difference in the average number of losses of $9 \mathrm{p}$ among the tumor stages $(\mathrm{P}<0.05)$.

HDs, that could provide important resources for identifying the locations of candidate TSGs in SCC. 
Table II. The different chromosomal recurrent minimal regions of genetic alterations on chromosome 9p in 22 SCCs.

\begin{tabular}{|c|c|c|c|c|}
\hline Regions & Gene contained in clones & $\begin{array}{l}\% \text { of }^{\mathrm{a}} \text { loss } \\
\text { in SCCs }\end{array}$ & $\begin{array}{l}\% \text { of hemizygous } \\
\text { deletion in SCCs }\end{array}$ & $\begin{array}{l}\% \text { of homozygous } \\
\text { deletion in SCCs }\end{array}$ \\
\hline 9p24.3-p24.1 & $\begin{array}{l}\text { JMJD2C, C9orf68, LOC403313, CDC 37L1, AK3, } \\
\text { JAK2, IGHEP2, PTPRD, FLJ35024, VLDLR, } \\
\text { ANKRD15, DMRT2, DMRT1, DMRT3, } \\
\text { LOC401490, LOC389702, C9orf66, DOCK8 }\end{array}$ & $\begin{array}{l}36.4 \% \\
(8 / 22)\end{array}$ & $\begin{array}{l}9.1 \% \\
(2 / 22)\end{array}$ & $\begin{array}{l}14.3 \% \\
(3 / 22)\end{array}$ \\
\hline $9 \mathrm{p} 21.3-\mathrm{p} 21.1$ & $\begin{array}{l}\text { ACO1, DDX58, LOC401497, SPINK4, BAG1, } \\
\text { CHMP5, TEK, C9orf14, C9orf11, CCDC2, } \\
\text { C9orf14, MLLT3, MTAP, FLJ35282, ELAVL2 }\end{array}$ & $\begin{array}{l}36.4 \% \\
(8 / 22)\end{array}$ & $\begin{array}{l}22.7 \% \\
(5 / 22)\end{array}$ & $\begin{array}{l}4.8 \% \\
(1 / 22)\end{array}$ \\
\hline
\end{tabular}

${ }^{\mathrm{a}}$ Alterations were defined by $\log _{2}$ ratio thresholds of -0.25 for copy number loss. ${ }^{\mathrm{b}}$ Alterations were defined by $\log _{2}$ ratio thresholds of $-0.5<$ $\log _{2}$ ratio $\leq-1$ for hemizygous deletion. ${ }^{c}$ Alterations were defined by $\log _{2}$ ratio thresholds of $<-1 \log _{2}$ ratio for homozygous deletion. Using this threshold, we generated a frequency table.

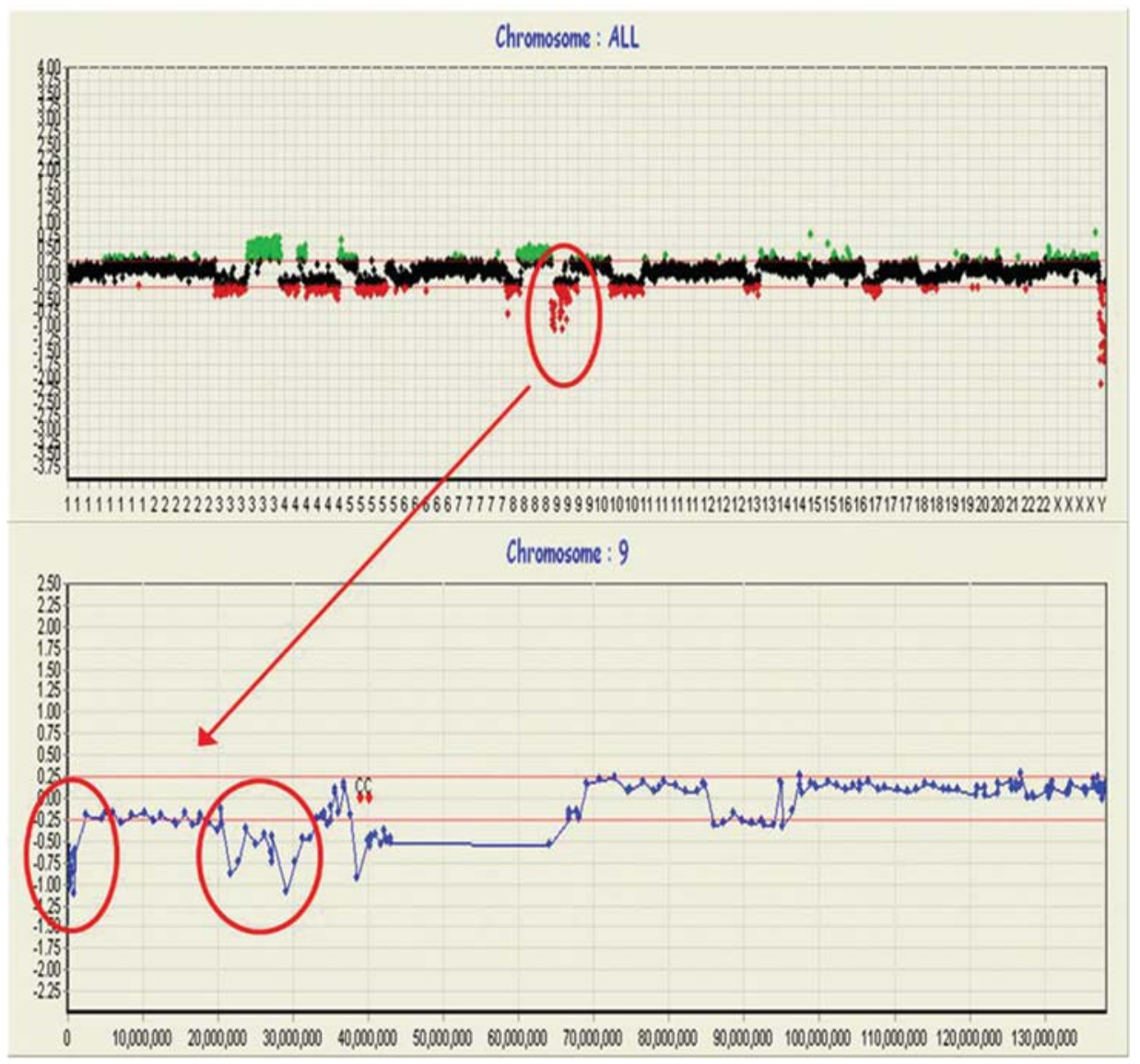

Figure 3. (A) Results of array-based CGH from a patient sample (tumor 17). Normalized $\log _{2}$ signal intensity ratios of the 4,046 clones were plotted on the basis of the chromosome position. Each dot represents the signal ratio for an individual BAC clone (dots with gains in green and losses in red). A log ratio $>0.25$ represents a genomic copy number gain, and a $\log _{2}$ ratio <- 0.25 represents a genomic copy number loss. The clones are ordered from chromosome $1 \mathrm{p}$ to 22q. (B) Genomic profiles of chromosome 9 from a patient sample (tumor 17). The vertical lines indicate a ratio of <-1 in this BAC clone, suggesting HD regions, i.e., 9 p24.3 and $9 \mathrm{p} 21.1$.

On examination of a genome-wide platform at a resolution of $1 \mathrm{Mb}$, we identified 2 independent $\mathrm{HD}\left(\log _{2}\right.$ ratio <-1) loci on chromosome $9 \mathrm{p}$, one spanning a $128-\mathrm{kbp}$ region on $9 \mathrm{p} 21.1[4.5 \%(1 / 22)]$, and the other spanning an appro- ximately $200-\mathrm{kbp}$ region on 9p24.3 [13.6\% (3/22)]. The representative genome profiles of the HDs on chromosome $9 \mathrm{p}$ are shown in Fig. 3. The whole genome profiles (A) are shown in the upper portion, and the individual chromosome 


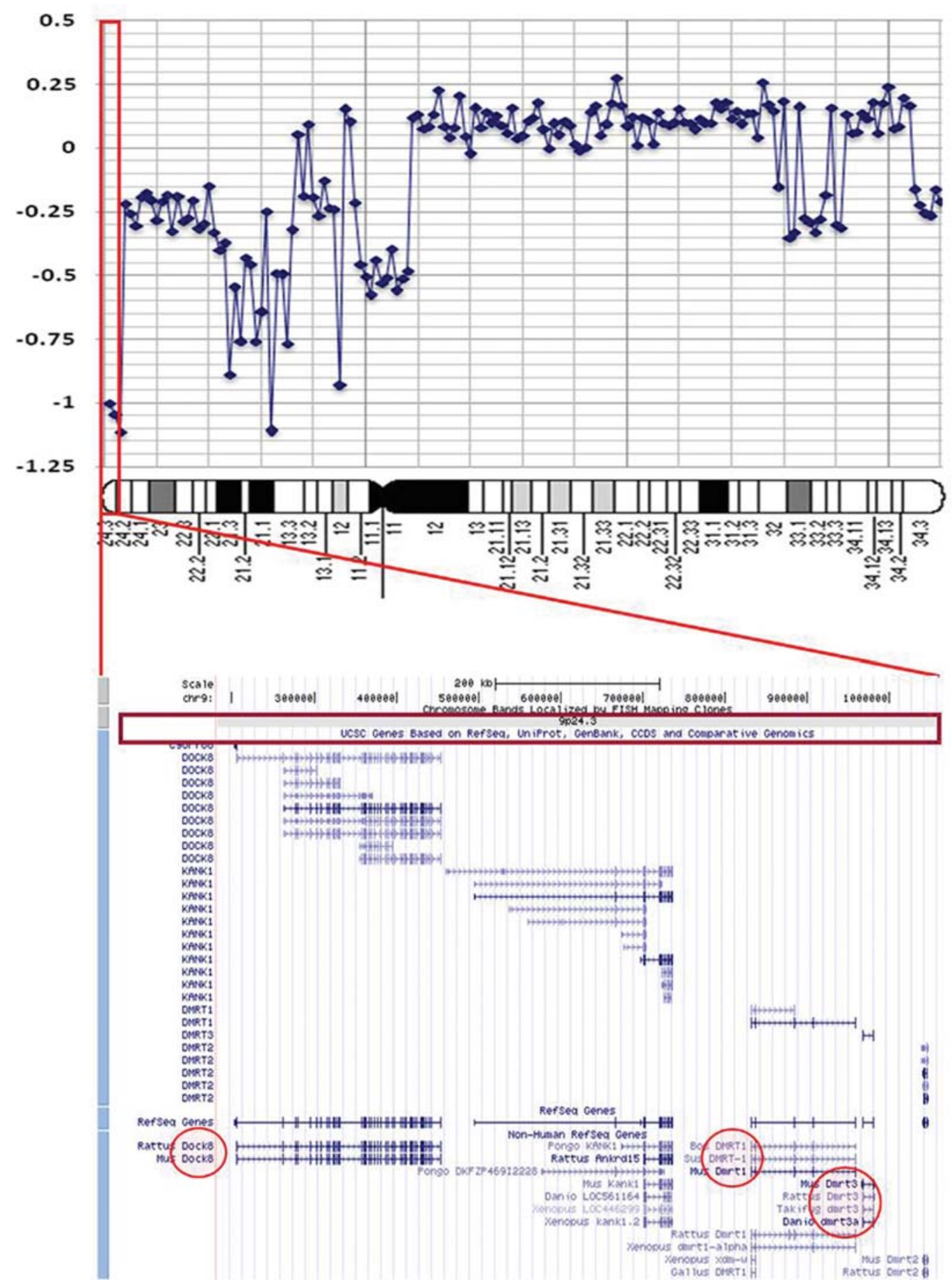

Figure 4. (A) Individual profiles of chromosome 9 showing the HDs at 9p24.3. The clones on chromosome 9 are arranged (pter-qter) based on the UCSC human genome (Mar 2006 Freeze). In the intensity ratio profiles, the X-axis represents the map position of the corresponding clone, and the intensity ratios are assigned to the Y-axis. The HDs at 9p24.3 are highlighted in red. (B) The minimum deleted region of 9p24.3 with the potential target genes in the 22 SCCs. The candidate genes are shaded in red.

profiles with the HD at the 9p24.3-p21.1 (B) are presented in greater detail in the lower portion.

We confirmed the presence of a previously recognized HD on chromosome 9p24.3, which has been shown to target DOCK 8 and spans 3 of the 5 deleted regions; this HD, therefore, appeared to be an excellent candidate for a TSG. The median span of the HDs was $120 \mathrm{kbp}$ (range: 94-152 kbp), and all HDs were located between BAC57-F05 and BACACN08. Furthermore, we identified 2 possible candidate TSGs, namely DMRT1 and DMRT3, at 9p24.3. The minimal common region identified by genome-wide array-CGH was located within a 112-kb length on chromosome 9. A 128-kbp HD region on 9p21.1 including all unknown genes was found in the SCC cases. The representative genome profiles of chromosome 9 with the HD at 9p24.3 are shown in Fig. 4A, and the minimum deleted region of $9 \mathrm{p} 24.3$ with the potential target genes, DMRT1, DMRT3 and DOCK8, in the 22 SCCs are shown in Fig. 4B. 
Table III. Primers used for quantitative real-time PCR analysis.

\begin{tabular}{lcll}
\hline Gene name & $\begin{array}{c}\text { Chromosome } \\
\text { location }\end{array}$ & \multicolumn{1}{c}{ Primer forward } & \multicolumn{1}{c}{ Primer reverse } \\
\hline DMRT1 & $9 \mathrm{p} 24.3$ & TGCTTCTCCCGCATGCT & GGCAGGGTCTGCTTAGGAAAG \\
$D M R T 3$ & $9 \mathrm{p} 24.3$ & CTGCCATCTGGGAAAGAACCT & AGCACGGCTATCCTCCAGATTTATA \\
$D O C K 8$ & $9 \mathrm{p} 24.3$ & CAAAGGAGCCATGAAGTGGAAAA & CCTTAGCTTTTTGCTGGAGTTCTGT \\
\hline
\end{tabular}
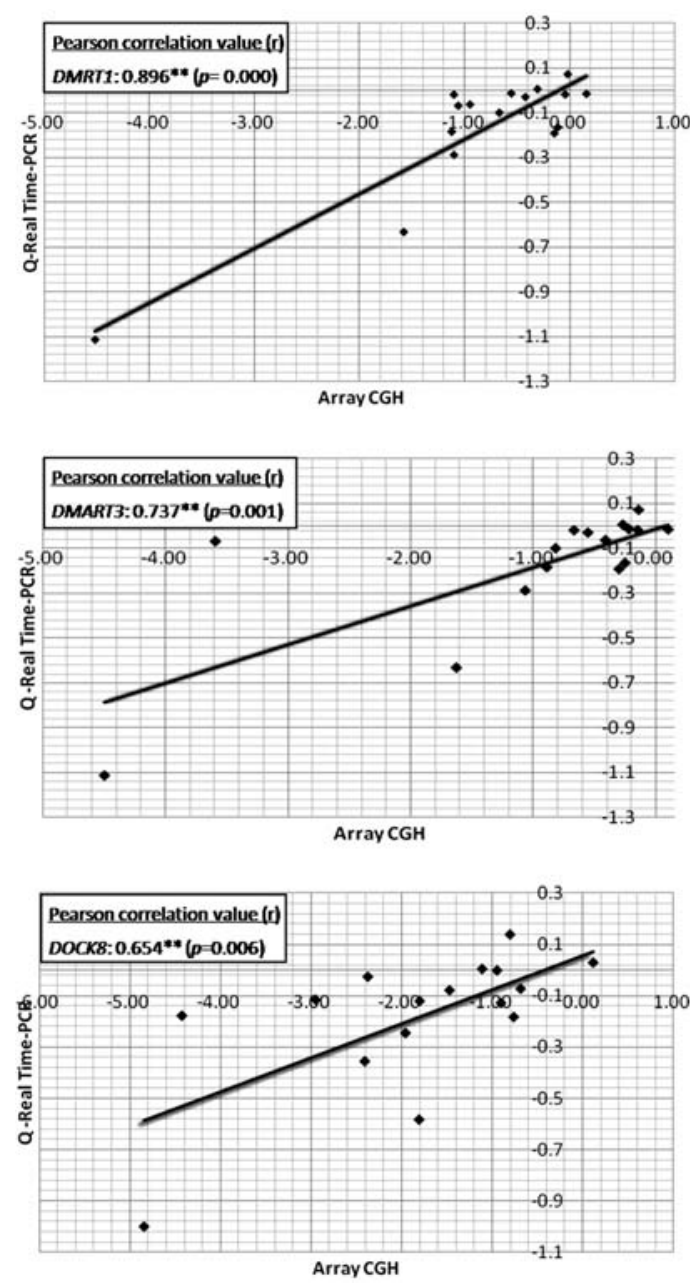

Figure 5. Correlation between the DMRT1,DMRT3 and DOCK8 copy numbers estimated by array-CGH (X-axis) and the gene expression level assayed by qRT-PCR (Y-axis) in the SCC cases. Each dark square represents the $\log _{2}$ ratio value of the clone containing one of these genes for one case. The correlation coefficient ( $r$ ) and the P-value are mentioned in the upper left-hand corner of the figure.

Validation of the expression levels of the candidate 9p24.3 TSGs by quantitative real-time PCR. We further conducted a quantitative real-time PCR (qRT-PCR) analyses for the 3 potential TSGs (DMRT1, DMRT3 and DOCK8) at 9p24.3 to demonstrate the consequences of the HDs identified by arrayCGH. The primers for the 3 genes (DMRT1, DMRT3 and DOCK8) are presented in Table III.

We found strong correlations between the qRT-PCR and array-CGH results. HD of the 3 TSGs (DMRT1,DMRT3 and $D O C K 8)$ at 9 p24.3 as revealed by array-CGH also showed a statistically significant correlations with their expression levels in the SCC samples. The correlation coefficients between the gene expression levels in qRT-PCR and the copy numbers estimated by array-CGH analysis for the 3 genes (DMRT1,DMRT3 and DOCK8) were 0.896, 0.737 and 0.654 , respectively $(\mathrm{P}<0.05)$. The values of array-CGH were depicted by linear-ratios, and the $\mathrm{N}$-value was delineated in qRT-PCR. Fig. 5 represents the scatter plot analysis of all the data points of the 3 genes, DMRT1, DMRT3 and DOCK8, based on array-CGH and qRT-PCR of the SCC cases.

\section{Discussion}

Array-CGH has been recognized as a successful and valuable tool for whole genome evaluation. The use of array-CGH allows determination of changes in the copy numbers of single genes or relatively small chromosomal regions, thus improving the resolution of traditional CGH and potentially facilitating more confident identification of new candidate genes (23).

Whole-genome array-CGH showed copy number losses on chromosome 9p in $72.7 \%(16 / 22)$ of the SCC cases, with common regions mapped to 9p24.3-p21.1. The short arm of chromosome 9 has long been suspected to include critical TSGs in lung cancer $(18,24-28)$. Pertersen et al (24) reported that in SCC of the lung, the most prevalent deletions with an incidence of $>50 \%$ were observed on chromosome $9 \mathrm{p}$, and Sato et al (25) also described the chromosome arm 9p as the most frequent target for HDs in lung cancer. More recently, a published study has shown the high incidence of copy number losses $(44 \%)$ on 9p in SCC detected by whole-genome array$\mathrm{CGH}$ (7). Taken together, these results and the findings of our study suggest the likelihood that the short arm of chromosome 9 harbors TSGs that are important in the pathogenesis of SCC and/or genomic features fragile during lung carcinogenesis.

Interestingly, copy number losses on chromosome 9p have been considered to be one of the major drivers of SCC progression. These observations prompted us to examine whether there exists a correlation between copy number losses on $9 \mathrm{p}$ and the clinicopathological parameters in SCC. We demonstrated that aggressive behavior of SCC, such as in advanced stages or poorly differentiated malignancies, is significantly associated with an increase in the copy number losses on $9 \mathrm{p}(\mathrm{P}=0.033)$. Recurrent copy number losses on $9 \mathrm{p}$ have been shown to be directly related to the tumor stage, preferentially detected in advanced tumors, and responsible for SCC progression. Wilkens et al described that certain genomic alterations that occur in early cancers may be 
responsible for tumor development, and the genomic alterations that are detected in advanced cancers are connected to tumor progression (27). These findings suggest that the disease stage or degree of histological differentiation could be estimated by an analysis of the genomic alterations on certain chromosomal regions prior to the initiation of treatment (18). Although this result supports previous findings that $9 \mathrm{p}$ loss is one of the major drivers of SCC progression, it also suggests the concept of a genomic stage and others routes of progression of SCC.

Whole-genome array-CGH at a resolution of $1 \mathrm{Mb}$ allowed the identification of 2 distinct HD $\left(\log _{2}\right.$ ratio < -1) loci on chromosome 9p: one, spanning a 128-kbp region on 9p21.1 $[4.5 \%(1 / 22)]$ and the other, spanning a $200-\mathrm{kbp}$ region on 9 p24.3 [13.6\% (3/22)]. The HD at 9p24.3 was found to contain the putative TSG, DOCK8. The DOCK 8 gene is thought to be one of the prime target genes on $9 \mathrm{p}$, and its reduced expression or HD has already been described in connection with various tumors, including lung cancer. Saelee et al (28) have reported under expression of the DOCK8 gene at 9p24.3 (44\%) in hepatocellular carcinomas and Takahashi et al (29) have documented the involvement of epigenetic down-regulation of DOCK8 in the development and/or progression of lung cancer. Taking together the results of this study with the findings of others, the DOCK 8 gene appears to be the most likely target for 9p24 HDs and can be defined as an independent target region for chromosome $9 \mathrm{p}$ deletions in various tumors including SCC.

In addition, we identified 2 possible candidate TSGs, DMRT1 and DMRT3, as novel potential targets for HDs at 9p24.3. To our knowledge, an HD at 9p24.3, the location of DMRT1 and DMRT3, has thus far not been documented in SCC; however, genetic mutations of DMRT1 and DMRT3 have commonly been found in different cancer types. Chen et al (30) suggested DMRT1 as a novel translocation partner of BCL6 in gastric lymphomas, and an aberrant methylation of the DMRT1 gene in gastric cancers has also been documented (31). More recently, in the study of Arora et al (32), DMRTI and EGFR were both shown to be direct targets of $E G R 1$, and $E G R 1$ bound to their promoters. Furthermore, the DMRT3 gene has been suggested as one of the target HDs at 9 p24.3 in lung cancer cell lines (33). These findings support our hypothesis that DMRT1 or DMRT3 may be potential TSGs in SCC. Therefore, an HD of DMRT1 or DMRT3 appears to be involved in the carcinogenesis of solid tumors, including SCC. Additional investigations are needed to address the molecular mechanisms of the tumor suppressor properties of DMRT1 or DMRT3 in SCC of the lung.

We subjected the three potential target genes of DMRT1, DMRT3 and DOCK8, to qRT-PCR analysis. Q-RT-PCR demonstrated array $\mathrm{CGH}$-detected candidate genes that were under expressed in SCCs, thereby showing great potential as candidates for predictive markers of SCC. Further functional and biological studies are expected to validate and evaluate the role of DMRT1 or DMRT3 as novel candidate TSGs in SCC in larger series and on multiple samples.

In the present study, we significantly extended previous findings and firmly established that aggressive clinical behavior and poor progression of SCC is strongly associated with the loss of the chromosome $9 \mathrm{p}$ arm. Furthermore, we confirmed a recognized HD at the DOCK 8 locus and identified 2 highly potent novel TSGs, namely DMRT1 and DMRT3, on the chromosome 9p24.3 HD target in SCC cases. These newly identified genes could provide a basis for further functional validation and might be the potential candidates for tumorigenesis in SCC.

\section{Acknowledgements}

The regional Research and Development Cluster Project (B0009735) funded by the Ministry of Commerce, Industry and Energy (MOCIE) of Korea financially supported this work.

\section{References}

1. Parkin DM, Bray FI and Devesa SS: Cancer burden in the year 2000. The global picture. Eur J Cancer 37 (Suppl. 8): S4-S66, 2001.

2. Rydzanicz M, Giefing M, Ziolkowski A, Kasprzyk M, Gabriel A, Dyszkiewicz W and Szyfter K: Nonrandom DNA copy number changes related to lymph node metastases in squamous cell carcinoma of the lung. Neoplasma 55: 493-500, 2008.

3. Choi YW, Choi JS, Zheng LT, Lim YJ, Yoon HK, Kim YH, Wang YP and Lim Y: Comparative genomic hybridization array analysis and real-time PCR reveals genomic alterations in squamous cell carcinomas of the lung. Lung Cancer 55: 43-51, 2007.

4. Sy SM, Wong N, Lee TW, Tse G, Mok TS, Fan B, Pang E, Johnson PJ and Yim A: Distinct patterns of genetic alterations in adenocarcinoma and squamous cell carcinoma of the lung. Eur J Cancer 40: 1082-1094, 2004.

5. Sos ML, Koker M, Weir BA, Heynck S, Rabinovsky R, Zander T, Seeger JM, Weiss J, Fischer F, Frommolt P, Michel K, Peifer M, Mermel C, Girard L, Peyton M, Gazdar AF, Minna JD, Garraway LA, Kashkar H, Pao W, Meyerson M and Thomas RK: PTEN loss contributes to erlotinib resistance in EGFR-mutant lung cancer by activation of Akt and EGFR. Cancer Res 69: 3256-3261, 2009.

6. Sharp TV, Al-Attar A, Foxler DE, Ding L, de A Vallim TQ, Zhang Y, Nijmeh HS, Webb TM, Nicholson AG, Zhang Q, Kraja A, Spendlove I, Osborne J, Mardis E and Longmore GD: The chromosome 3p21.3-encoded gene, LIMD1, is a critical tumor suppressor involved in human lung cancer development. Proc Natl Acad Sci USA 105: 19932-199327, 2008.

7. Boelens MC, Kok K, van der Vlies P, van der Vries G, Sietsma H, Timens W, Postma DS, Groen HJ and van den Berg A: Genomic aberrations in squamous cell lung carcinoma related to lymph node or distant metastasis. Lung Cancer (In press).

8. Marsit CJ, Wiencke JK, Nelson HH, Kim DH, Hinds PW, Aldape K and Kelsey KT: Alterations of $9 p$ in squamous cell carcinoma and adenocarcinoma of the lung. association with smoking, TP53, and survival. Cancer Genet Cytogenet 162: 115-121, 2005.

9. Todd S, Franklin WA, Varella-Garcia M, Kennedy T, Hilliker CE Jr, Hahner L, Anderson M, Wiest JS, Drabkin HA and Gemmill RM: Homozygous deletions of human chromosome $3 p$ in lung tumors. Cancer Res 57: 1344-1352, 1997.

10. Andujar P, Wang J, Descatha A, Galateau-Sallé F, Abd-Alsamad I, Billon-Galland MA, Blons H, Clin B, Danel C, Housset B, Laurent-Puig P, Le Pimpec-Barthes F, Letourneux M, Monnet I, Régnard JF, Renier A, Zucman-Rossi J, Pairon JC and Jaurand MC: p16(INK4A) inactivation mechanisms in nonsmall-cell lung cancer patients occupationally exposed to asbestos. Lung Cancer (In press).

11. Anna L, Holmila R, Kovács K, Gyorffy E, Gyori Z, Segesdi J, Minárovits J, Soltész I, Kostic S, Csekeo A, HusgafvelPursiainen K and Schoket B: Relationship between TP53 tumour suppressor gene mutations and smoking-related bulky DNA adducts in a lung cancer study population from Hungary. Mutagenesis (In press).

12. Tseng RC, Hsieh FJ, Hsu HS and Wang YC: Minimal deletion regions in lung squamous cell carcinoma: association with abnormality of the DNA double-strand break repair genes and their applications on gene identification and prognostic biomarkers. Lung Cancer 59: 332-339, 2008. 
13. Varella-Garcia M, Gemmill RM, Rabenhorst SH, Lotto A, Drabkin HA, Archer PA and Franklin WA: Chromosomal duplication accompanies allelic loss in non-small cell lung carcinoma. Cancer Res 58: 4701-4707, 1998.

14. Kang JU, Koo SH, Kwon KC, Park JW and Kim JM: Identification of novel candidate target genes, including EPHB3, MASP1 and SST at 3q26.2-q29 in squamous cell carcinoma of the lung. BMC Cancer 9: 237, 2009.

15. Kim JI, Lee JH, Seo JS, Hwang KT, Han W, Cho J, Lee JW, Ko E, Kim EK, Jung SY, Jeong EM, Bae JY, Kang JJ, Yang SJ, Kim SW and Noh DY: Genomic copy number alterations as predictive markers of systemic recurrence in breast cancer. Int J Cancer 123: 1807-1815, 2008.

16. Choe J, Kang JK, Bae CJ, Lee DS, Hwang D, Kim KC, Park WY, Lee JH and Seo JS: Identification of origin of unknown derivative chromosomes by array-based comparative genomic hybridization using pre- and postnatal clinical samples. J Hum Genet 52: 934-942, 2007.

17. Kim JI, Ju YS, Park H, Kim S, Lee S, Yi JH, Mudge J, Miller NA, Hong D, Bell CJ, Kim HS, Chung IS, Lee WC, Lee JS, Seo SH, Yun JY, Woo HN, Lee H, Suh D, Lee S, Kim HJ, Yavartanoo M, Kwak M, Zheng Y, Lee MK, Park H, Kim JY, Gokcumen O, Mills RE, Zaranek AW, Thakuria J, Wu X, Kim RW, Huntley JJ, Luo S, Schroth GP, Wu TD, Kim H, Yang KS, Park WY, Kim H, Church GM, Lee C, Kingsmore SF and Seo JS: A highly annotated whole-genome sequence of a Korean individual. Nature 460: 1011-1015, 2009.

18. Chochi Y, Kawauchi S, Nakao M, Furuya T, Hashimoto K, Oga A, Oka M and Sasaki K: A copy number gain of the $6 \mathrm{p}$ arm is linked with advanced hepatocellular carcinoma: an arraybased comparative genomic hybridization study. J Pathol 217: 677-684, 2009

19. Willenbrock $\mathrm{H}$ and Fridlyand J: A comparison study: applying segmentation to array CGH data for downstream analyses. Bioinformatics 21: 4084-4091, 2005.

20. Oshiro A, Tagawa H, Ohshima K, Karube K, Uike N, Tashiro Y, Utsunomiya A, Masuda M, Takasu N, Nakamura S, Morishima Y and Seto M: Identification of subtype-specific genomic alterations in aggressive adult T-cell leukemia/lymphoma. Blood 107: 4500-4507, 2006.

21. Kresse SH, Skårn M, Ohnstad HO, Namløs HM, Bjerkehagen B, Myklebost $\mathrm{O}$ and Meza-Zepeda LA: DNA copy number changes in high-grade malignant peripheral nerve sheath tumors by array CGH. Mol Cancer 7: 48, 2008.

22. Jardin F, Ruminy P, Kerckaert JP, Parmentier F, Picquenot JM, Quief S, Villenet C, Buchonnet G, Tosi M, Frebourg T, Bastard C and Tilly $\mathrm{H}$ : Detection of somatic quantitative genetic alterations by multiplex polymerase chain reaction for the prediction of outcome in diffuse large B-cell lymphomas. Haematologica 93: 543-550, 2008
23. Dehan E, Ben-Dor A, Liao W, Lipson D, Frimer H, Rienstein S, Simansky D, Krupsky M, Yaron P, Friedman E, Rechavi G, Perlman M, Aviram-Goldring A, Izraeli S, Bittner M, Yakhini Z and Kaminski N: Chromosomal aberrations and gene expression profiles in non-small cell lung cancer. Lung Cancer 56: 175-184, 2007.

24. Petersen S, Aninat-Meyer M, Schlüns K, Gellert K, Dietel M and Petersen I: Chromosomal alterations in the clonal evolution to the metastatic stage of squamous cell carcinomas of the lung. Br J Cancer 82: 65-73, 2000.

25. Sato M, Takahashi K, Nagayama K, Arai Y, Ito N, Okada M, Minna JD, Yokota J and Kohno T: Identification of chromosome arm $9 p$ as the most frequent target of homozygous deletions in lung cancer. Genes Chromosomes Cancer 44: 405-414, 2005.

26. Shibukawa K, Miyokawa N, Tokusashi Y, Sasaki T, Osanai S and Ohsaki Y: High incidence of chromosomal abnormalities at 1 p36 and 9p21 in early-stage central type squamous cell carcinoma and squamous dysplasia of bronchus detected by autofluorescence bronchoscopy. Oncol Rep 22: 81-87, 2009.

27. Wilkens L, Flemming P, Gebel M, Bleck J, Terkamp C, Wingen L, Kreipe $\mathrm{H}$ and Schlegelberger B: Induction of aneuploidy by increasing chromosomal instability during dedifferentiation of hepatocellular carcinoma. Proc Natl Acad Sci USA 101: 1309-1914, 2004

28. Saelee P, Wongkham S, Puapairoj A, Khuntikeo N, Petmitr S, Chariyalertsak S, Sumethchotimaytha W and Karalak A: Novel PNLIPRP3 and DOCK8 gene expression and prognostic implications of DNA loss on chromosome 10q25.3 in hepatocellular carcinoma. Asian Pac J Cancer Prev (In press)

29. Takahashi K, Kohno T, Ajima R, Sasaki H, Minna JD, Fujiwara T, Tanaka $\mathrm{N}$ and Yokota J: Homozygous deletion and reduced expression of the DOCK8 gene in human lung cancer. Int $\mathrm{J}$ Oncol 28: 321-328, 2006.

30. Chen YW, Hu XT, Liang AC, Au WY, So CC, Wong ML, Shen L, Tao Q, Chu KM, Kwong YL, Liang RH and Srivastava G: High BCL6 expression predicts better prognosis, independent of BCL6 translocation status, translocation partner, or BCL6-deregulating mutations, in gastric lymphoma. Blood 108: 2373-2383, 2006.

31. Jee CD, Kim MA, Jung EJ, Kim J and Kim WH: Identification of genes epigenetically silenced by $\mathrm{CpG}$ methylation in human gastric carcinoma. Eur J Cancer 45: 1282-1293, 2009.

32. Nagayama K, Kohno T, Sato M, Arai Y, Minna JD and Yokota J: Homozygous deletion scanning of the lung cancer genome at a 100-kb resolution. Genes Chromosomes Cancer 46: 1000-1010, 2007.

33. Arora S, Wang Y, Jia Z, Vardar-Sengul S, Munawar A, Doctor KS, Birrer M, McClelland M, Adamson E and Mercola D: Egr1 regulates the coordinated expression of numerous EGF receptor target genes as identified by ChIP-on-chip. Genome Biol 9: R166, 2008. 